Portland State University

PDXScholar

Spring 6-9-2016

Does the School Day Matter? The Association

Between Adolescent School Attachment and Involvement and Adult Criminal Behavior

Madeline O'Neil

Portland State University

Follow this and additional works at: https://pdxscholar.library.pdx.edu/open_access_etds

Part of the Criminology Commons, and the Education Commons

Let us know how access to this document benefits you.

Recommended Citation

O'Neil, Madeline, "Does the School Day Matter? The Association Between Adolescent School Attachment and Involvement and Adult Criminal Behavior" (2016). Dissertations and Theses. Paper 2990.

https://doi.org/10.15760/etd.2991

This Thesis is brought to you for free and open access. It has been accepted for inclusion in Dissertations and Theses by an authorized administrator of PDXScholar. Please contact us if we can make this document more accessible: pdxscholar@pdx.edu. 
Does the School Day Matter? The Association Between Adolescent School Attachment and Involvement and Adult Criminal Behavior

by

Madeline O’Neil

A thesis submitted in partial fulfillment of the requirements for the degree of

\author{
Master of Science \\ In \\ Sociology
}

Thesis Committee:

Lindsey Wilkinson, Chair

Melissa Thompson

Dara Shifrer

Portland State University

2016 


\begin{abstract}
:
Research with adolescence demonstrates school involvement and attachment greatly influences students' outcomes and choices outside of their school environment. Many studies have addressed whether delinquent behavior while in adolescence is associated with various aspects of schooling, but there is limited research looking at the long-term effects schooling has on criminal behavior in adulthood. The purpose of this study was to assess whether students' attachment to their school or involvement in extracurricular activities at school shapes students' outcomes in adulthood — specifically their criminality and likelihood of being arrested. In addition, this study took on a gendered relationship, examining how gender moderates the associations between attachment and adult crime, and involvement and adult crime. The study took a quantitative approach using Waves 1 and 4 of the National Longitudinal Study of Adolescent Health. Findings indicate that a student's attachment to school is negatively associated with the likelihood of being arrested as an adult. In addition, the likelihood of adult criminal behavior is negatively associated with student's school involvement. Lastly, in this study I found that gender acts as a moderating mechanism between attachment and criminality, as well as sports involvement and arrested as an adult. Thus, this research adds to the established field, which has demonstrated how school involvement and attachment improve outcomes in adolescence, by showing that these positive experiences impact downstream outcomes such as criminal behavior in adulthood.
\end{abstract}


Table of Contents

ABSTRACT

List of Tables

INTRODUCTION

LITERATURE REVIEW

SOCIAL BONDS

SCHOOLS/JUVENILE SCHOOLS

SCHOOL INVOLVEMENT $\quad \mathbf{8}$

SCHOOL ATTACHMENT 12

METHODOLOGY 16

$\begin{array}{ll}\text { DATA } & 16\end{array}$

MEASURES

ANALYTIC APPROACH 21

\begin{tabular}{lr} 
RESULTS & 23 \\
\hline
\end{tabular}

\begin{tabular}{lr} 
DISCUSSION & 31 \\
\hline
\end{tabular}

$\begin{array}{ll}\text { LIMITATIONS } & \mathbf{4 0}\end{array}$

\begin{tabular}{ll} 
CONCLUSION & 42 \\
\hline
\end{tabular}

REFERENCES 
List of Tables:

Table 1: Analytic Sample Characteristics.................................... 46

Table 2: Logistic Regression of Arrested as an Adult (Models 1-3).....................47

Table 3: OLS Regression of Criminality as an Adult (Models 1-3) .....................49 


\section{Chapter 1: Introduction}

Over the last few decades, research has documented a trend in which school institutions rely more heavily on punishment than on prevention (Goldson \& Muncie 2006). This paper explores how students' school-based involvement and school attachment is associated with crime and deviant behavior in adulthood. School-aged adolescents are believed to spend 40-50\% of their time inside of school (Mahoney 2006). Thus, school serves as an institution that dramatically shapes the interactions and choices of adolescents. Within schools, students are shaped into young adults by teachers, administrators, and curriculum; these school activities are intended to create proactive and responsible future members of society. This is done through many channels of learning, such as within classrooms, outside of classrooms, through friendships, attachments to school personnel, and involvement in school activities such as clubs and sports (Broh 2002, Eccles 2003, Hoffman et. al 2013). Through the combination of these opportunities and interactions students are believed to learn the values of teamwork, individual and group responsibility, physical and mental endurance, competition, diversity and culture, and a sense of community (Dumais 2008). Recent research suggests students who are attached in school and/or engaged in extracurricular activities have increased positive outcomes in school, and decreased likelihood of school failure and dropping out (Dumais 2008).

Past research has used Hirschi's (1969) theory of social control to help explain youth's participation or lack of participation in crime. This theory posits that the strength of an adolescent's social bond to conventional society will determine whether he or she 
will engage in conforming behavior or delinquent behavior (Hirschi 1969). The social bond consists of four elements: attachment, commitment, involvement, and belief. According to Hirschi each element of the social bond acts individually to strengthen the social bond, but when all four elements are at work the social bond is the strongest. Attachment represents the closeness between children and important pro-social individuals or pro-social institutions in their lives. Involvement highlights the interactions a youth has with the positive socializing institutions or activities. It is these conventional activities (such as athletics, clubs, community service) that bonds individuals to institutions and where prosocial norms are reinforced and therefore lower involvement in delinquent activities (Hirschi 1969). Commitment indicates the degree of which a person sees the social values and norms as legitimate and worthy. Lastly, belief indicates acceptance and adherence to the social norms and values. Based on Hirschi's definitions on the foundations of social bond there appears to be two groups- - the social component (attachment and involvement) and a more internal/individualized component (commitment and belief). The social component explains more the social influence and ties to society an individual can experience, whereas commitment and belief highlight more the internalization and replication process of the social bond development.

This present study however, is not attempting to test Hirschi's theory, but instead I am using aspects of his theory on social control to construct the framework for my study. I am exploring two elements of the social component of the social bond theoryattachment and involvement — in order to explore the connection they have with limiting adulthood crime. As previously stated measuring all four elements of social bond results 
in the strongest test, however for the purpose of this study I am looking at how outside social influences impact the social components of the social bond-attachment and involvement.

Decades later, this theory still holds sway in sociology and criminology, as prosocial activity involvement and institutional attachment have been found to be important factors that reduce delinquency and crime in the adolescent years(Ackers and Sellers 2004). However, most of the existing research on the association between school activities and attachment focus on youth's current outcomes and less on long-term outcomes. In addition, the research that does examine long-term outcomes, longitudinally, looks more at prosocial behaviors such as college graduation, higher paying jobs, and successful marriages (Eccles et al. 2003; Stuart 2011), and less on crime and deviance. The goal of my research is to better understand the association between students' involvement and attachment to school in adolescence and their levels of crime and deviance in adulthood. Researchers and educators have concluded that children who engage in delinquent behavior and are not involved in societal conventions are more likely to engage in deviant behavior as adults (Stuart 2011, Mahoney et al. 2006, Sampson \& Laub 1990). Environments, schools for example, play a large factor in determining and shaping outcomes for adolescents as they enter adulthood (Hawkins et al.1992). In addition, Hoffmann et al. (2013) found greater improvement in school achievement and a weakening of delinquent behavior when youth were more attached to school. Hirishi (1969) supports that developing positive attachments is negatively associated with deviant behavior, therefore I hypothesize that students who are more 
positively attached to school will have less criminal behavior throughout their lives (Hirschi 1969).

There is evidence from previous literature that suggests gender affects how individuals interact within a school setting that can lead to varying outcomes of attachment and involvement. Males tend to put less emphasis on relationship building compared to females, which leads to different impacts of attachment (Laundra et al. 2002). Simultaneously, the research shows that involvement as well tends to have a gendered difference; this research highlights that males tend to receive negative effects from involvement in sports, whereas females tend to receive positive outcomes from sports (Clark 2012).

This present research examines how school attachment and involvement are associated with adult criminality, in addition to exploring the moderating relationships that gender has with the predicting variables. While the current literature shows evidence of the positive impact attachment and extracurricular activities have on students' outcomes, there is limited research on how students carry these concepts and activities into adulthood and the impact they have on the longitudinal outcomes of the adulthood criminal behavior of the students. Thus, I examine the following research questions: 1. Is adolescent school attachment associated with adult criminality and the likelihood of being arrested in adulthood? 2. Is adolescent school extracurricular involvement, including sports only, clubs only, or sports-clubs mixed involvement, associated with adult criminality and the likelihood of being arrested in adulthood? 3. Does gender moderate these associations? 


\title{
Chapter 2 Literature Review
}

\author{
Social Bonds
}

My general framework for explaining how student's attachment to school and involvement in school decrease criminal behavior in adulthood draws from the theory, social control; the theory states everyone is criminally inclined, but for a person to be persuaded away from crime they must have strong social bonds. This paper only explores two elements of the social bond—attachment and commitment. Hirschi asserts that all are inclined to do crime, but strong social bonds encourage conformity and thus discourage deviation from social norms. This theoretical approach suggests that youth who participate become attached to pro-social people/institutions and/or are involved in organized activities will have less of a draw to delinquent acts and will ultimately be encouraged to conform to social norms, thus increasing their positive life outcomeshigh paying jobs, better careers, marriage, and less engagement in crime (1969).

Since the law requires youths to attend school, the quickest and most efficient way to have students create social bonds is through school programs such as clubs or sports, in addition to strong bonds with faculty. Research shows coaches and teachers often have high levels of affection and respect from their students, and students will often create strong positive attachments to them (Thornberry et al. 1991). These attachments generally discourage antisocial behavior and increase the ties students have to the conventional social order (1991). According to the theory of social control, individuals with a high degree of attachment to a conventional family and the conventional 
institution of school will be more likely to care what others think of them and act accordingly (Hirschi 1969). Therefore, attachment to others acts as a tool to socialize and reinforce the norms that are expected when interacting in the social world (Thornberry et al. 1991).

This theory also asserts the importance of involvement in social conformities and activities on developing strong social bonds. Agnew and Peterson (1989) found that after-school activities require a significant amount of time for a student and subsequently the student has less time to engage in delinquent acts. This falls in line with Hirschi's theory, which asserts that by being involved with pro-social activities, an adolescent will not have the time or opportunity to be deviant. Hirschi also explains the importance of being involved in a prosocial activity, as students involved learn what is expected from them by the society around them and thus the involvement positively affects their life outcomes.

Schools

A large body of literature frames schools as an institution aimed at developing cognitive ability, connectedness, and general engagement, which are thought to lead to better outcomes in adulthood (Collishaw et al. 2007; Loukas et al. 2010). The schools that provide a greater variety of activities, learning styles, and participation, see better academic achievement and greater student success. When students have more opportunity to expand their skill sets they will in turn be more marketable and hold more social capital as they move through life. Having access to activities that encourage and 
motivate decision-making processes has been found to have more positive behavioral outcomes in adolescence and early adulthood (Cauffman \& Steinberg, 2000), and when lacking those processes often can lead to worse life outcomes—risky behavior, lowpaying jobs, and not graduating from high school. In addition to helping students progress their lives in a positive manner, Roth, Brooks-Gunn and Galen (1997) found that schools that sponsor positive youth development programs---clubs and organizationssee a decline in risky behavior of students. Literature on crime links negative school experiences — bad teacher and peer relationships, lack of a connection to activities, and not feeling welcomed - with an increase in delinquency and risk behavior in adolescence (Moore and Halle 2001).

\section{Juvenile Detention Schools}

Currently, the United States has the highest rate of juvenile incarceration, with nearly $16 \%$ of all arrests per year being people under the age of 18 (Snyder 2004). Juvenile detention centers and juvenile academies have been shifting their discipline style from punitive to rehabilitative (Mendel 2001) —school, hands on activities, therapy, better adult-child interaction, etc. While this institution is not exactly like the traditional school setting, the results that this change has accomplished for the delinquent youth has helped to decrease the recidivism rate (ETS 1996). Research has found that when juveniles are exposed to positive school settings, in the detention centers, and opportunities they are more likely to be employed, have better behavior, and less likely to end up in prison (ETS 1996). With these findings indicating that the "hardest" of youth can leave crime through engaging in positive developmental activities, one can 
reasonably assume that similar interactions could occur in the traditional school setting. My research plans to find this connection in the traditional school setting by examining students' level of attachment and their involvement in school and seeing if an association exists between attachment and involvement and subsequent criminal behavior in adulthood.

\section{Student Involvement}

As stated by Metsapelto \& Pulkkinen (2012):

Extracurricular activities refer to adult-supervised activities that are unrelated to the primary curricula, provide opportunities for participants to develop specific skills or knowledge, and take place outside of school hours. (p.11)

With the increase in debates and conflict, about education reform, within the US education system and the increased push for standardized test scores and common core, researchers have found that what happens inside the classroom is not the only factor critical for student success (Snellman et al. 2015). Eccles et al. revealed in their study in 2003 that participation in organized activities teaches skills and social networking that correlates to enhancement in students' educational achievement, well-being, healthy choices, and prosocial behavior while in school. What is lacking from this research is the investigation of the longterm impact the development of these skills and social norms, through the involvement in school activities, have on limiting the criminal choices and antisocial choices of the students as they become adults.

With a rise in higher expectations of academic performance, there has been a decrease in extra-curricular opportunities for students, especially at schools with higher rates of poor academic performance (Stuart 2011). When students have access to 
activities that are not directly focused on academics, they have higher levels of hands-on skills, higher self-esteem, and greater investment in their success (Kaufman and Gabler 2004; Stuart 2011). Students who participate in programs centered on the arts, community involvement, or sports have higher rates of college enrollment (Kaufman and Gabler 2004). Researchers agree extracurricular activities participation has a positive impact for youth such as higher educational attainment, greater future earnings, and increased civic engagement (Snellman, et al. 2015, Sampson \& Laub 1990, Lander 1978).

There has been debate on whether involvement in a breadth of activities or passionate involvement in a few programs has differing impacts on a youth's life outcomes. One line of thought is that participation in a broad range of activities can help to prepare youth with a variety of skills and facilitate exposure to diverse people and experiences (Agans et al. 2014). In contrast, there is research to suggest that too much diversity can result in poor outcomes, because youth may be spread too thin (Marsh and Kleitman 2002). Despite the latter information, the dominating line of thought in research is that youth who participate in a range of activities have demonstrated more favorable life and behavioral outcomes than youth who participated in fewer activities (Mahoney et al. 2006, Stuart 2011). This variation in activity leads to higher rates in advanced skills and networking ability in addition to decreased risky behavior and substance abuse (Mahoney et al. 2006). There has been much research that focuses on youth activity involvement and the association it has with adolescent outcomes, but more research is needed to examine the long-term influence of extra-curricular activities. 
We know that participation in extra-curricular programs is genuinely enjoyed and viewed as a positive experience among youth (Guest 2009). By allowing the opportunities for "out of the classroom" learning, students are able to invest in their own futures and feel that they are in control of their own destinies through the activities they have chosen (2009). The assumption for allowing non-academic programs in school is that this type of indirect learning provides a positive structure for a student's growth, thus increasing the student's positive life outcomes. It creates future proactive members in society and the choice of activities gives the student a feeling of independence (Agnew and Petersen 1989; Landers 1978), which is important for youth development (Wankel and Berger 1990). Educational institutions in the United States can create successful students who positively shape the future of the country, but can also fail students by not providing them encouragement or access to the tools to build a well-rounded individual. Much of the literature on extracurricular activity is done through exploring a combined examination of sports and clubs involvement, for this reason a review of the literature on the differing outcomes of sports and clubs is needed.

\section{Involvement in Sports}

Being involved in sports while in adolescence is thought to maintain and increase physical and emotional health of youth (Anderson and Butcher 2006). Sports also have been found to increase leadership, educational achievement, and motivation (Eitle 2005). In other research, however, a positive association between sports participation and positive behaviors has not been found. Rather, it has been suggested that sports participation creates problems in the classroom and increases risky behavior (Cahn 1993; 
Martin, 1998). Sports have been found to increase various aspects of deviance: drinking, poor test scores, anger issues, etc. (Kaufman and Gabler 2004). In my research I will explore the association between being involved in only sports extracurricular activities and the likelihood of being arrested as an adult and criminality in adulthood.

\section{Sports and Gender}

In high school and middle school sports students become separated by gender, thus resulting in the possibility of different experiences of sports for girls and boys. As children enter high school the impact of gender socialization manifests differently in girls and boys through the involvement in sports (Slavkin 2001). For instance, boys are thought to be more likely to conform to the pressures of masculinity (tough, strong, proud), which can lead to increased interactions with risky behavior (Slavkin 2001). In contrast, sports for girls have been found to be associated with increasing girls' beliefs in themselves, their independence, and overall confidence (Clark 2012). The different outcomes that sports are shown to have, dependent on gender, could likely manifest differently for students as they reach adulthood. Females tend to receive beneficial qualities and traits from sports, which are known to tie individuals to society in a prosocial manner, thus leading to less involvement in crime as adults. In contrast, because sports are shown to increase risky behavior for males as youth, the assumption then is that males would be more likely to carry these traits into adulthood. Therefore, I hypothesize that females who are involved in sports will have a lower likelihood of being arrested as an adult and report less criminality as an adult compared to men. 


\section{Involvement in Clubs}

Some examples of clubs schools offer are music, art, chess, language clubs, science clubs, honor society, model UN, etc. There is little research investigating the association between involvement in school clubs only and positive outcomes for students - better grades, higher rates of graduation, etc. Involvement in school-based extracurricular activities has been a point of study for many researchers; however, this concept generally includes sports, or researchers have looked at youth participation in only sports. Little research has examined the association between clubs on involvement and student outcomes.

\section{Student Attachment}

Research has shown that positive adult-child relationships are positively correlated with better child outcomes; thus, negative adult-child relationships are associated with higher behavior problems and poorer child outcomes - dropping out of school, authority issues, etc. (Devers 2014). Research indicates that students who have negative parent relationships, have lower socioeconomic status, or have been abused show better life outcomes when they have a strong relationship with a non-parental adult (Noam \& Fiore 2004) — such as teachers or coaches. Attachments are imperative in a youth's life, in that these connections are how they learn to act in society (Hirschi 1969). In addition these affections towards people can often act as guiding models that lead youth away from deviant behavior. School attachment has long been recognized as an important attribute for youth to possess within school. Studies suggest that feeling a close 
attachment to school is associated with higher academic achievement (Strolin-Goltzman et al., 2014), increased positive behavior in school (2014), and less reports of substance abuse (2014). Conversely, Hirschfield \& Gasper (2011) have found that weaker attachments to school can result in higher rates of in-school misconduct, skipping school, and dropping out. In a study conducted by Northeastern University in 2008 they found:

Students who view their academic environment as positive are less likely to be involved in serious delinquency or risky behavior. The converse is also true when students feel negatively about their school, they are more likely to exhibit negative behavior (p. 1).

Within the school setting, school attachment represents a student's bond to his/her teachers and peers. A vast amount of research demonstrates how a quality relationship between student and teacher positively influences student behavior and achievement in school. (Arum 2005). A student's attachment level is found to thrive when there is respect and trust between students and school staff, and in turn students are more likely to accept the school's values (Bassinette 2004). The level of attachment a student has to her/his school has been used as an indicator of academic success and is widely believed to predict success in the future (Coker and Borders 2001). When students have a positive pro-social role model or a positive outlook on people around them, it greatly increases their pro-social attachments (Noam \& Fiore 2004). When students create strong bonds to adults who believe in and commit to social conventions - not stealing, not hurting people, being honest, etc. - the student then internalizes this behavior and repeats it as she/he get older, thus leading to less deviance and crime in adulthood (Hirschi 1969). 
Unfortunately, while this body of literature agrees that attachment is an important factor in behavioral outcomes for youth, the impact of school attachment on adult outcomes has not been fully examined (Lilly 2011; Maddox \& Prinz 2003; Bassinette 2004).

\section{School Attachment and Gender}

A 1979 study by Hagan, Hewitt, and Alvin found that social control is a highly gendered process, with girls often having higher levels of attachment and greater benefits from attachment than boys. This gendered difference in attachment is thought to be a response to gender role socialization (Thornberry et al. 1991). The impact social control—attachment—is believed to be most influential in the adolescent years, which coincides with the development of deviant behavior being most likely to occur (Hagan 1979). Females have been found to put more emphasis and time into developing their socials bonds, such as attachment (Hagan 1979; Laundra et al. 2002); females tend to emphasize more time and value on relationship development. With attachment being more heavily emphasized in the adolescent experience for girls, there is an assumption that the latent effect could be at play with females having an added protective factor against criminal behavior as an adult, as a result of putting more emphasis on the importance of attachment and relationships. Greater attachment leads to better outcomes, whereas less attachment generally results in worse life outcomes; however, little research has explored the longterm moderating association between attachment and gender. In this research I will examine the longitudinal relationship that gender has on moderating the association between attachment and criminality and likelihood of arrest in adulthood. 
Hypotheses

With the literature supporting the importance that attachment to pro-social people and institutions have for the development of youth, I hypothesize students who feel more attached to school will be less likely to be arrested as an adult; in addition I believe I will see that students with higher attachment will report less criminality as an adult. As school-based involvement in extracurriculars is supported by past research, as to it being beneficial for outcomes for youth while in school, I hypothesize that a youth involved in school-based extracurriculars will report less criminality and be less likely to be arrested as an adult. I hypothesize that gender will act as a moderating variable between attachment and the dependent variables, arrested as an adult and criminality as an adult. An increase in attachment will result in a greater protective factor on females; hypothesizing that females who have higher attachment will have a lower likelihood of being arrested and will have less criminality as an adult compared to men. Lastly, I hypothesize gender will moderate the association between sports involvement and adult criminal behavior; meaning the associaiton between sports involvement and adult criminal behavior will be stronger among women. 


\section{Chapter 3 Methodology:}

To test the hypotheses, this study analyzed data from the public use version of the National Longitudinal Study of Adolescent to Adult Health (Add Health), a nationally representative, school-based study of 7 th to 12 th grade students who were first interviewed during the 1994-1995 school year (Wave I) and followed up in 1995-1996 (Wave II), in 2001 (Wave III) and in 2008 (Wave IV). The original Add Health sample of 12,105 was drawn from a random sample of high schools and middle schools in the United States that were stratified by region, urbanicity, size, type, racial composition, and grade span (Harris 2007). Add Health provides researchers an opportunity to follow adolescents in to adulthood, and includes measures of adolescent school attachment and involvement in Wave 1, when respondents were 12-18 years of age, as well as measures of criminal justice involvement in adulthood in Wave IV, when most respondents were between the ages of 26 and 32 .

The analytic sample is limited to the sample size from the public use data $(\mathrm{n}=$ 5,114) and to respondents who participated in both Waves I and IV. I then excluded respondents who were missing from Wave IV because my dependent measures are measured in Wave IV, when respondents were adults. This results in the loss of 1,390 respondents, thus giving a sample size of $n=3,724$. Those not participating in Wave IV were more likely than those participating in both Wave I and Wave IV to be black and male. Finally, excluding missing variables_-values were missing on ever arrested as an adult--resulting in an analytic sample of 3,614. 
Selection bias is a concern for this sample, in that it is possible the respondents who participate in school activities are already more pro-social, so in actuality it is not the involvement that is "causing" the reduction in criminal behavior; rather, something unmeasurable is the mechanism resulting in more involvement and less crime. Despite this bias, the decision to examine attachment and involvement while in school is that these two concepts are believed to tie people to conventional society. What the students can gain from attachment and involvement (skills, norms, independence, self-esteem), are thought to shape an individual and thus those concepts are carried with them through adulthood and continue to shape their choices and thoughts. Being involved in activities, such as chess club, honor society, or debate teach children valuable skills that can often be applied later in life through career choices, college choices, etc. These mechanisms are carried throughout the life of the respondent and are believed to increase the respondent's social ties and thus leading to less crime.

Independent Variables

School Attachment. Attachment can go both ways, as was discussed earlier, however for the purpose of this study I focus on positive school attachment. The purpose of focusing on positive attachment is that in order to keep people from acting criminally, Hirschi posits that positive pro-social attachments must be formed. Thus, school attachment was measured by averaging the Wave I in-school student reports of positive connectedness to various aspects of school. Based on a 5-point Likert scale ranging from strongly agree to strongly disagree, each respondent was asked to assess their agreement with the following five indicators: You feel close to people at your school; you feel like you are part of your school; you are happy to be at your school; the teachers at your 
school treat students fairly; and you feel safe in your school (alpha=.79). This index is a modified version of Resnick et al. (1997) attachment variable and ranges from one to five with one indicating low attachment and 5 indicating high attachment.

Involvement. School involvement is measured using four exclusive variables created from a series of questions from the Wave I in-school survey that ask respondents to identity which thirty-three extracurricular school activities they participated in during the current school year. The four exclusive categories of involvement include sports only activities, clubs only activities, mixed activities, and no activities (Kort-Butler and Hagewen 2011). With each activity I ran correlations between the type of activity and the dependent variables arrested as an adult and criminality as an adult, in order to ensure that the groupings were as similar as possible; cheerleading/dance was one activity that is often discussed as to whether it qualifies as a sport or not. Upon running the correlations with the dependent variables I found that cheerleading had more similar results to the other sports, therefore I defined cheerleading/dance as a sport.

1. Baseball/Softball

2. Basketball

3. Field Hockey

4. Football

5. Ice Hockey

6. Soccer

7. Swimming

1. Band

2. Book Club

3. Chorus

4. Computer Club

5. Debate

6. Drama

\section{Sports Only Activities}

8. Tennis

9. Track

10. Volleyball

11. Wrestling

12. Cheerleading/dance

13. Other Sports

Clubs Only Activities

7. French Club

8. Future Farmers

9. German Club

10. History Club

11. Honor Society

12. Latin Club 
13. Math Club

14. Newspaper

15. Orchestra

16. Science Club

Dependent Variables
17. Spanish Club

18. Student Council

19. Yearbook

20. Other Club

Arrested as an adult. Arrested as an adult is measured using the Wave IV survey question that asked respondents if they were "arrested over the age of 18 " [1=yes and $0=$ no]. Those who say "yes" are coded as having been arrested as an adult. All others are coded as not being arrested in adulthood. The decision to use arrested as an adult as a dependent variable was that in today's society being arrested holds weight in how an individual navigates through society. In order to get employment most employers ask if an applicant has ever been arrested and often that information is used to eliminate a candidate (Pager 2007). Being arrested over the age of 18, regardless of the reason, will have consequences and repercussions for the individual. These consequences can shape an individual's life and have negative results in the quality of life they can lead—leading to unemployment, poverty, limited access to public assistance, etc. (Pager 2007; Travis 2002). For this reason I find arrested as an adult to be a good outcome variable, in that if the connection to pro-social school attachment and school involvement exists it can in turn result in lowering the likelihood of being arrested as an adult and improve the outcomes for individuals.

Adult Criminality. Adult deviant behavior was measured by adding responses to twelve questions from the Wave IV survey that assessed how often the respondent had engaged in the following activities in the current year: damaged property that was not yours, stole something worth more than $\$ 50$, stole something worth less than $\$ 50$, broke 
into someone's house to steal something, used a weapon to get something, was part of a physical fight, stole property, sold property that was not yours, used someone's credit card without permission, deliberately wrote a bad check, sold drugs, or hurt someone bad enough to go to the hospital $($ alpha $=.74)$. Response choices for each type of criminal activity included $0=$ never, $1=$ one or two times, $2=$ three or four times, $3=$ five or more times, resulting in adult criminality score ranging from 0-36.

Criminality is an aspect of oneself that an individual can hide from friends, family, and the public, thus it can be difficult to truly know how much crime a person engages in by pure observation. By measuring the self-reported crime of respondents, I hope to gain a more accurate measurement to the true criminal behavior that an individual partakes in their adult life. Finding a correlation between adolescent experiences and a decrease in criminality would result in having a better understanding of how a person navigates through their life based partially on their school attachment and school involvement.

Control Variables

Demographic characteristics of respondents. In order to accurately assess the association between adolescent school attachment and involvement and adult criminality, I control for the socio-demographic characteristics of respondents. Using information from the Wave 1 in-home survey, I include variables for race-ethnicity, gender, age, and socioeconomic status. Gender, age, race, and ethnicity and parent's level of education were all pulled directly from Wave 1 . Each respondent in the survey was able to choose 
multiple race categories; for this reason I used a racial hierarchy scale to assign one race category per respondent, e.g. black, Native American, Asian, other, and then white. I identify those who are Hispanic and then all others (non-Hispanic) are identified as nonHispanic. The parents in Wave 1 report their own education levels, although the survey does not identify which parent it is, but rather identifies parent responses as the primary parent. This could be a limitation as the primary parent is likely to be the parent who stays home with the children and could be the less educated of the parents, which could skew the findings.

In addition, I control for adolescent deviance when predicting adult outcomes. When an individual is deviant as a youth, they are at a greater risk to continue this trend into adulthood, for this reason I felt it necessary to control for crime as a youth in order to ensure that any crime as an adult was not a result of a continuance of crime from the adolescent years. The adolescent deviance variable was operationalized using the similar questions as the adult criminality variable. The adolescent deviance variables also includes the following three questions - "I skipped school," "I lied to my parents," and "I have been in a group fight." The 15 variables derived a Cronbach Alpha score of .829. Each deviant act was rated on a four-point scale: $0=$ never, $1=$ one or two times, $2=$ three or four times, 3 = five or more times. The 15 variables were summed so each individual would have a criminality score from 0-45.

\section{Analytic Approach}

I start the analysis by presenting descriptive statistics for all analytic variables as well as bivariate associations between my primary independent variables and dependent 
variables. Specifically, I examine the association between school involvement and attachment and adult criminality and arrest. In order to further assess the significance of these bivariate associations after controlling for adolescent delinquency and sociodemographic controls, I conduct a series of OLS regression models predicting adult criminality and logistic regression models predicting the probability of being arrested in adulthood.

Model 1 and Model 2 examine the association between the dependent variables (arrested as an adult \& criminality as an adult) and the independent variables (attachment $\&$ involvement typology) without the inclusion of the other. Model 3 for each outcome (criminality and adult arrest), regresses the dependent variables on my primary independent variables—school attachment and school involvement. Model 4 includes the socio-demographic controls, and lastly, Model 5 includes adolescent criminality to assess the association between school attachment and involvement and the dependent variables after controlling for adolescent deviance. Lastly, I add interaction terms between attachment and gender, involvement and gender in Model 6. 


\section{Chapter 4 Results}

Descriptive Analysis

Weighted descriptive statistics for students' measures of the independent variables, the dependent variables, and the control variables are presented in Table 1. Attachment scores of respondents have a mean value of 3.57 and a standard deviation of .85. The attachment index ranges from $0-5$, with 0 meaning not attached at all and 5 indicating completely attached; a score of 3.57 falls between moderately attached to highly attached. The frequencies for involvement indicate that $24.2 \%$ of respondents were involved in sports, $20 \%$ were involved in clubs, $35.3 \%$ were involved in mixed (clubs and sports) activities, and, lastly, 14.2\% of respondents indicated no involvement in any sports or clubs. The remaining $6.3 \%$ were missing on the adolescent involvement variable. Approximately $51 \%$ of the sample was female, and $49 \%$ was male. The racial breakdown of the analytic sample is the following: $67 \%$ of the sample is white, $15 \%$ is black, 3.3\% is Asian, 4\% is Native American, and 7\% is "other" race; the remaining percentage was missing information. $11 \%$ of the sample identified as Hispanic. Approximately $29.9 \%$ of the parents identified they had attended at least some college. The variable measuring the respondent's criminality as a youth had a mean value of 3.3, which means the average amount of criminal acts a respondent engaged in as a youth was approximately 5 or more crimes.

[Table 1 here] 
Multivariate Regression

I present two different regression analyses — one is logistic regression measuring the association between school attachment and involvement and the dummy variable, ever arrested in adulthood. The other type of regression analysis I present is linear regression, which examines the association between school attachment and involvement and the continuous criminality variable. Both of the regressions are structured in the same manner. Model 1 shows that association between school attachment and likelihood of being arrested in adulthood and adult criminality. Model 2 shows individual association between school involvement and the likelihood of ever being arrested and adult criminality and the likelihood of ever being arrested. Model 3 includes both the attachment and involvement independent variables to assess the independent effects of each. Model 4 introduces controls for age, gender, race, and parent education. Model 5 introduces the continuous variable measuring the respondent's criminality as a youth. Finally, Model 6 includes the interaction terms between gender and school attachment and involvement.

Logistic Regression-Predicting Arrests as an Adult

\section{Likelihood of Arrested as an Adult by School Attachment as a Youth}

School attachment significantly affects the likelihood of a respondent being arrested as an adult when all other variables are held constant. As results in Model 1 suggest there is a negative association between adolescent attachment to school and selfreported arrests in adulthood - for every one unit increase in attachment the likelihood of 
reporting an arrest in adulthood decreases by $22.2 \%$. As the Models progress attachment remains statistically significant. In the final Model, when all variables are held constant with every one unit increase in attachment respondents were $13 \%$ less likely to be arrested as an adult $(\mathrm{p}<.001)$.

\section{Likelihood of Arrested as an Adult by Sports Involvement as a Youth}

Sports only involvement is not associated with the dependent variable, likelihood of being arrested as an adult. However, I do find that the association between sports involvement and likelihood of arrest as an adult is moderated by gender: while women, on average, are less likely to be arrested, women who are involved in sports are $50.3 \%$ less likely to report ever been arrested over the age of 18 , compared to men and women who were not involved in sports. In addition, this result illustrates that sports involvement acts as a protective factor for women, whereas for men is has no effect on the likelihood of being arrested as an adult. This result suggests that sports are more beneficial for women in relation to creating a lower likelihood of being arrested as an adult.

\section{Likelihood of Arrested as an Adult by Clubs Involvement as a Youth}

Participation in only clubs while in adolescence has a significant effect on the likelihood of being arrested as an adult. In Model 2, students who reported only being involved in clubs were $20 \%$ less likely to report being arrested in adulthood, relative to those with no extracurricular involvement. Consistent with previous Models, clubs only activity remained significant at the $\mathrm{p}<.001$ level in Model 5; suggesting when all else is 
held constant the odds of clubs only respondents reporting being arrested as an adult is $45 \%$ lower than those with no involvement. This finding confirms hypothesis 4 , which states that clubs only involvement, would be negatively associated with the likelihood of being arrested as an adult.

\section{Likelihood of Arrested as an Adult by Mixture of Clubs and Sports Involvement as a} Youth

When students are in a mixture of at least one sport and one club while in school they are less likely to report being arrested as an adult. Model 2 highlights involvement in a mixture of a sport and a club is negatively associated with the likelihood of being arrested as an adult; those with mixed involvement were $41.8 \%$ less likely to report being arrested compared to those that were not involved in a school-based activity. In Model 5, highlighting the main effects shows, the odds of mixed activity respondents reporting being arrested as an adult decreased by $25 \%$ for every unit increase in the mixed activity. This result confirms the hypothesis that a mixture of involvement would show to have a lower likelihood of arrests as an adult.

\section{Likelihood of Arrested as an Adult by Controls}

Model 4, when all else is held constant, black respondents are 44\% more likely than whites to report ever being arrested in adulthood. Model 5 shows the estimated effect of youth criminality was statistically significant $(\mathrm{P}<.001)$, supporting literature suggesting that when students engage in crime as a youth they are more likely to continue 
that trend into adulthood, which increases the chances of being arrested (Childs et al. 2011).

[Table 2 here] 
OLS Regression-Criminality as an adult

\section{Criminality as an Adult by School Attachment as a Youth}

Students who have higher attachment to school have significantly lower criminality as an adult, compared to less attached students. In Model 1, I find that attachment to school has a negative and statistically significant association with criminality as an adult $(b=-.012, p<.001)$, which indicates that higher levels of attachment are associated with a decrease in criminality as an adult. In Model 3, when type of involvement is held constant, attachment to school shows significantly less adulthood criminality $(b=-.012, p<.001)$, compared to those that are less attached. In Model 6, with the inclusion of the interaction terms with gender, respondents who had higher levels of attachment to school reported lower levels of adult criminality $(b=-.014$, $\mathrm{p}<.001$ ). While, on average, those that have higher attachment engage in less crime as an adult, women who are attached are even less likely to engage in criminal behavior as an adult $(b=-.013, p<.01)$, suggesting a stronger negative impact of school attachment on adult criminality for women than for men. These results indicate gender does moderate the association between attachment and criminality as an adult since the interaction between gender and attachment is statistically significant.

\section{Criminality as an Adult by Sports Involvement as a Youth}

Being involved in sports while in school has a marginally significant relationship with criminality as an adult. In Models 2 and 3, sports involvement was not found to have any significance with criminality as an adult. However, in Model 4, respondents 
who reported only being involved in sports in school had a decrease in criminality as an adult $(\mathrm{b}=-.013, \mathrm{p}<.05)$, compared to students that were not involved. In Model 5 highlighting the main effects I found marginal significance, illustrating that being involved in a sport while in school lessened the amount of crime a respondent engaged in as an adult $(\mathrm{b}=-.014, \mathrm{p}<.1)$.

\section{Criminality as an Adult by Clubs Involvement as a Youth}

With all other variables held constant, involvement in only clubs as a youth significantly decreases adulthood criminality. Clubs only participation, in Model 2, found that these students reported less crime as an adult $(b=-.019, p<.001)$, compared to less attached students. In Model 5, the clubs only variable remained significant $(b=-$ $.016, \mathrm{p}<.001$ ), supporting the hypothesis that clubs only respondents would engage in less criminality as an adult. Therefore, this shows that being involved in clubs, regardless of demographics, is associated with less criminality as an adult.

\section{Criminality as an Adult by Mixture of Clubs and Sports Involvement as a Youth}

Involvement in a mixture of at least one club and one sport shows to significantly decrease the amount of criminality a person engages in as an adult. In Model 2, mixed extracurricular activities $(b=-.017, p<.001)$ reports lower levels of adult criminality, compared to those not involved in any extracurricular activities in adolescence, suggesting a negative association between participating in a mixture of sports and clubs and adult criminality. This relationship remained significant throughout the Models, indicating that a mixture of sports and clubs involvement is negatively associated with 
criminality as an adult. When youth participate in at least one of each type of school activity they engage in less crime as adults, compared to respondents who were not involved in extracurricular school activities as youth.

Model 4 highlights that females report less adult criminality. As well in Model 4, the control variable for age, consistent with the idea of "aging out of crime," is statistically significant, suggesting that as respondents get older they report less crime. I also saw that Hispanic respondents are more likely than non-Hispanics to engage in more crime as adults. In Model 5, respondents who had higher levels of criminal behavior as youth reported higher levels of criminality as adults $(\mathrm{B}=.004 ; \mathrm{p}<.001)$. Youth who engage in crime are more likely than youth not engaged in crime to continue acting criminally as they grow older (Gottfedson and Hirschi 1990). 


\section{Chapter 5 Discussion}

The purpose of this study was to examine how students' attachment to school and involvement in school extracurricular activities is associated with criminality and involvement with the criminal justice system in adulthood. Previous studies have examined the relationships that exist between attachment and/or involvement and adolescent deviance, as well as the positive benefits that come from involvement and/or attachment such as higher paying jobs and higher graduation rates. The present study builds on this literature by examining the long-term impact of school attachment and/or extracurricular involvement on various elements of adult deviance, including criminality and arrests. Results indicate that adolescent attachment and involvement in clubs or involvement in a mixture of one club and one sport are moderately to highly associated with a negative relationship with criminal behavior in adulthood (less likely to be arrested and a decrease in criminality). In addition, I found that sports only involvement was associated with a marginally significant relationship with a decrease in criminality. As well I found that sports only involvement by women resulted in this population being less likely to report being arrested as an adult. The results underscore the importance of positive interactions and experiences as a youth have on the development of these future adults and in turn the development of society. The results from this study found that there is some connection between a student's attachment and involvement while in school and their future relationship with criminal behavior as an adult, thus I argue that as a society, by shaping our education system to have all school systems foster student 
attachment and give access to extracurriculars, we will see less engagement in criminal activity in our future adult population.

Arrested in Adulthood

\section{School Attachment}

According to previous research a student's attachment to school increases the student's achievement while in school (Strolin-Goltzman et al. 2014), in addition to decreasing risky and problematic behavior while in school (Devers 2014). These attachments help teach youth the social norms and what is expected of them by the social world, which leads to not acting criminally, as acting criminally is not valued by society (Hirschi 1969). In this present study the results found that higher levels of school attachment is negatively associated with the likelihood of being arrested as an adult, suggesting that when a student is more attached to their school they will have less involvement with the criminal justice system in adulthood. Arrested as an adult represents criminal actions that are not supported or valued by society, and getting arrested represents breaking a social rule/norm. Therefore, when respondents indicated higher attachment to school, in adolescence, they were less likely to report being arrested in adulthood, thus showing that these attachments lead to strong ties to conventional society. When holding a respondents race, ethnicity, gender, parent's education, age, and criminality as a youth constant, their attachment in school is still found to be negatively associated with the likelihood of arrest in adulthood. Overall, respondents who had been arrested over the age of 18 had a lower level of attachment while in school, with the converse relationship being true as well, which is consistent with previous research. 
The impact that school has shows there is a longitudinal relationship with a lower likelihood of arrests. By creating a school system that encourages and supports students being able to build strong attachments to their school, as a society we are able to help decrease the number of arrests as these students grow older and therefore increasing the amount of civic and social citizens that are walking the streets. The faculty and staff within a school are the people that students interact with day in and day out; therefore these individuals will be imperative to a school in order to be able to increase attachment of the students. Giving more support and training to our teachers in order for them to be more prepared, as well having smaller class sizes will give the teachers the flexibility and capability to get to know each student on a more personal level, thus increasing access to attachment.

Arrest in Adulthood

School Involvement

$\underline{\text { Sports Only }}$

A typology of involvement while in school had a more diverse portfolio of effects. A sports only typology while in school indicated nearly no association until the moderating effect of gender was introduced. What was found showed that female respondents who were involved in sports were less likely to be arrested as an adult, compared to their male counter parts. This finding suggests that being involved in a sport is beneficial for girls in lowering the likelihood of being arrested over the age of 18 . The literature on this topic suggests females who are involved in sports have an increase in 
believing in themselves, independence, and overall confidence, all of which limit deviance and risky behavior (Clark 2012). This increase in independence and self-esteem is likely to be acting as a protective factor for females, who internalize these concepts and then take them into adulthood. This finding shows how central a sport can be in helping develop a female student in a positive way. These enriching qualities that sports create for females: independence, confidence, self-esteem, could be one driving force as to why they are less likely to be arrested when they reach adulthood. For this reason it is important to continue strengthening and enforcing female sports in the school system, as well as encouraging girls to get involved in sports.

\section{Clubs Only}

Involvement in clubs only, while in school, was associated with a decreased likelihood of being arrested as an adult, compared to respondents who were not involved in school-based extracurriculars. With little previous investigation into the effects that clubs only have on a student's behavior and outcomes, this study found that when a student is involved in only clubs during school-aged years they will not be arrested as often in adulthood, compared to their peers that were not involved in an activity. Of the three typologies of involvement the clubs only respondents reported the least amount of arrests, compared to those not involved; being $57 \%$ less likely to report being arrested. Also, this result may provide evidence toward what previous studies have found, that increased involvement encourages building skills and social connections (Bassinette 2004), which leads to engaging in less problematic behavior. Further analysis of the implications that clubs have on a policy level will be discussed later in this paper. 


\section{Mixed Activity}

Mixed activity involvement, which were students that reported at least one sport and one club, reported less arrests as an adult, compared to respondents that were not involved in a school-based activity. Prior literature suggests that involvement in a breadth of activities leads to developing advanced skills and networking that have resulted in more favorable life and behavioral outcomes (Mahoney et al. 2006, Stuart 2011). The result from this current, as well, helps add to the literature by supporting that a range of activities leads to decreased risky behavior (Mahoney 2006) and the decreased chances of being arrested as an adult. Further analysis of the policy repercussions will come later in the paper.

\section{Criminality as an Adult}

\section{School Attachment}

The previous literature was limited on the investigation of a student's attachment to school and the long-term trajectory that this attachment has on decreasing criminal behavior as the students reach adulthood; this present study addressed this gap. Results showed that the more/higher a student was attached to their school they were less likely to report criminality as an adult. This is to say that respondents who were more attached to school, as youth, reported less criminality in the past 12 months, compared to less attached students. Hirschfield \& Gasper (2011) found that students who had weaker attachment to school were more likely to engage in delinquent behavior as a youth, such as school misconduct, skipping school, and dropping out. In my research, when holding 
this criminality as a youth constant, the strong attachment to school continued to have a negative association with criminality as an adult. Thus, this research supports the hypothesis that adolescent attachment to school decrease criminality as an adult.

The moderating relationship between gender and attachment was found to exist, which supports the hypothesis that females who are attached will have a greater decrease in crime, relative to males. While attachment, in general, is negatively associated with criminality, the estimated effect of attachment on criminality is even greater among females than among males. It is believed that relatedness and connectedness are more critical for the development of girls social functioning (Henrich, Kupermine, Zohar, \& Leadbeater 2001), whereas they are not believed to be as strong for boys. While females tend to desire quality connections in order to thrive, males tend to thrive with confirmation of status and strength (2001). The literature further explains how attachment tends to be stronger in females than males because of the desire for connection that females have (2001). Because women tend to put more importance and emphasis on the relationships they make, those attachments are then carried with them into their adult lives and in turn act as mechanisms to decrease how much crime they do. Since males tend to not put as much emphasis on building these bonds, the impact of attachment then is likely not going to hold as much of a protective factor for them.

Implications for this are that while attachment is important for the development of females, there needs to be further exploration of how we encourage attachment for male students so that these bonds can have a greater impact on their futures. Even though the male respondents in this study who had high attachment were less criminal as adults, it is 
important to find ways to shape a school setting so that attachment through different techniques are available to all students. This could be a limitation of the study in that attachment to school was measured using only five questions of attachment, however there could be other elements within the school institution that help develop school attachment.

\section{School Involvement}

\section{Sports Only}

In the final Model sports only involvement showed marginal significance with a decrease in criminality as an adult for respondents who participated in a sport while in school. However in Model 4 and Model 5 respondents who had reported being involved in a sport saw a moderately significant decrease in criminality as an adult. Within these models the controls for race and youth criminality are included; with the inclusion of these variables, sports only involvement became significant at $p<.05$. Racial minorities are more likely to be in sports and to commit crime in adulthood, so when I controlled for race the protective effect of sports is highlighted, showing that involvement in sports decreases criminality as an adult. In the United States, African American youth and Hispanic youth have higher rates of street crime than Whites (Unnever \& Gabbidon, 2011) and more likely to be arrested. When race and criminality were held constant we saw that participation in sports had a protective factor-those that were involved in sports regardless of race and criminality as youth saw a decrease in criminality as an adult. 
This is an important finding in that the implication for giving minority youth sports to be involved in could result in less criminality for the community and surrounding areas. With sports acting as a tool to decrease how criminal an individual becomes, policies need to be in place to ensure that schools can offer every student the opportunity to be involved in a sport. With the average cost of a single sport in high school being $\$ 250$ for a student (Wyrwich 2009), low income and high-risk students do not have the funds to participate and receive the many benefits that come from being in a sport. With less money going into the Physical Education budget and school sponsored sports (Gamoran 1990, Price 2010), as well as sports costing more money to be a part of, there is a risk of seeing an increase in criminality as these students grow into adults. I strongly advise that a revamp of the education system needs to include proper funds and allotted time for the students to participate in a sport.

\section{Clubs Only}

Involvement only clubs in adolescents was statistically significantly and negatively associated with criminality in all of the OLS regression. Overall, respondents who had been involved in only clubs in their adolescent years reported less criminality as an adult. These findings are theoretically compelling as theory has identified that students participating in activities that center on positive youth development will increase a student's life outcomes, in turn decreasing their deviance (Gilman 2001). This study builds on theory by adding in empirical evidence supporting that clubs (a PYD program) discourage involvement in criminality as an adult, thus increasing a student's pro-social choices and behavior as an adult. 


\section{Mixed Activity}

Similar to the results for clubs only, a mixture in at least one sport and one club, while in school, was found to have a negative association with adulthood criminality. This finding supports the Zill et al. (1995) study, which found 5-19 hours per a week of extracurricular activities showed a decrease in risky behavior for the student. What this new result indicates is that mixed activity not only decreases bad behavior during the school-aged years, but that it has a long-term effect on decreasing anti-social behavior (fighting, theft, etc.). I found that the students who were able to participate in one of each type of involvement were less likely to self-report criminality as an adult. Schools that offer both types of involvement to students see positive results in their student bodies' behavior and achievement while they attend the school (Dumais 2008, Stuart 2011). This has a latent effect on the student, where the student continues to not engage in deviance as they grow older, thus reports less criminality as an adult. With the school system putting more emphasis on academics and test scores, students have less time to engage in non-academic based programs (sports and clubs), which could mean that students will not receive the benefits that come from this type of involvement (more skills and social networking, etc.), which can eventually lead to higher levels of criminality as these youth enter adulthood. While academics are of course an important aspect of school, we must not let that be the only focus that the school day is for students. 


\section{Limitations}

Limitations of this study require discussion. First, the measurement of adult criminality was constructed between the ages of 24-35. By age 30 the vast majority of young people will have ceased or significantly reduced their criminal activity and settled into the "norms" of society (Bachman et al. 2002). The age of offenders committing crime spikes in the early to mid-twenties, and then sharply declines. This means that respondents were in the period of "aging out of crime." The questions for the variable measuring criminality asked the respondents have you committed specific crimes within the last 12 month, thus it could not accurately measure how criminal they were in their earlier years, when they are more likely to act criminally.

The current study suggests that both school attachment and school involvement play important roles in the adulthood outcomes of criminality and arrests of the respondents. Adolescents were only asked during the first survey if they were currently involved in an activity at school; therefore if a student was participating in club sports or organizations like Boy Scouts, Girl Scouts, 4h, etc. In addition, because students were only asked at this one point in time on involvement in school, the study could not account for students that joined an activity later or students who quit their activities. Questions remain regarding a student's involvement while in school and could be further dissected using other datasets that follow students throughout each year of high school and beyond.

The respondents from Wave IV that dropped out of the study had slightly higher rates of criminality as youth compared to the analytic sample. This acts as a limitation in that by the time of Wave IV it is likely that a percentage of the respondents who had the 
highest rates of adult criminality could have been arrested and then incarcerated. This would affect both of the dependent variables, since these respondents were not included in the final sample size due to not being able to complete the survey.

Moreover, while Add Health continues to follow the same cohort of respondents, the first wave was first conducted in 1994. For this reason, the dataset is outdated based off of the policy and funding changes within the education system. These changes could result in different outcomes for the new cohorts of students, thus the results from this study may have different results for new cohorts. Furthermore, the data for the dependent variables was all self-reported criminal activity; therefore the measurements for criminality and arrests could be skewed based off of how truthful respondents were about their behavior.

This research focused on the social component of the social bond, and did not explore the internal/individual components—commitment and belief. Future direction for this study would be to explore the entire scope of Hirschi's theory of social control, by using all four elements as prediction measurements. This current study found that the elements of attachment and involvement do act as protective factors against deviance as an adult. In the next phase of the study I can measure the relationship that youth commitment and belief have with adult criminal behavior in order to further dissect the strength of social bond on shaping people. Because these four foundations tend to overlap and influence one another a study that explores the broader scope of their impact would possibly highlight even stronger associations. 


\section{Chapter 6 Conclusion}

Despite its limitations, this analysis clearly shows attachment to school and involvement in school-based activities act as defenses against the possibility of a respondent engaging in criminal behavior as an adult. Education is a topic many sociologists are passionate about and this is evident by the amount of literature available on the topic. My research combines and connects many already established claims from the literature. We know that extracurricular activities are beneficial to a student's future success; we know that students need to fill their time with pro-social activities; we know that students who do not engage in these activities have higher levels of deviance; and we know that strong positive attachments lead to strong social conventions. No research though has studied the direct role that schools have in these factors and how these factors may be leading to or decreasing criminality when the student reaches adulthood.

The results from this study indicate that school attachment and involvement in clubs or mixed involvement in a club and a sport decreases the rate that respondents reported adulthood criminality, as well as the likelihood of being arrested over the age of 18. In many ways these findings do not appear to be shocking or coming from left field, yet with the prior knowledge to the importance school institutions play on a student at school-aged time, it did seem shocking that there had been little investigation on the longitudinal influence school attachment and school-based involvement have on limiting criminal behavior. This research highlights the interconnectedness that the criminal justice system and educational institutions have with one another. By this research finding a connection between adolescent activities and future adulthood crime outcomes 
a conversation about educational policy change is the responsible decision for our society to have as the next step — some such steps could be increasing funding, reshaping the education budget to our schools in order to provide more access to school-based programs, as well as changing the amount of students that are allowed in a single class. When teachers have 30 plus students in a classroom it is unreasonable to expect them to be able to give individualize attention and support to a student in order for the student to build a positive attachment.

As has been found in literature, strong parental attachments help tie youth to the conventional world (Devers 2014), however not all youth have positive relationships with their parents. This research found that there is an association between a student's attachment to their school and criminal outcomes as an adult (likelihood of being arrested and criminality). The students who had higher attachment to their school were less likely to report being arrested as an adult and they had a decrease in criminality when they had higher attachment. With many students not able to form strong bonds with their parents (Noam \& Fiore 2004), school could be the missing key in solving the problem in a lack of attachment students have with their parents or guardians. Changing the family structure is nearly impossible for governmental policy; however the government and states have more control over the school day process. In order to increase the benefit that attachments have on bonding a person to society, the school setting can fill the gap that is lacking in students' lives that do not develop positive attachments at home. The attachments that students create to their school are shown to follow the student 
throughout their adult life and in turn we see that students had lower rates of criminal behavior as an adult.

Much of the evidence of the associations between extracurricular participation and life course outcomes has been based on research that does not separate clubs by the exclusive effect that they have on student outcomes. This study expands this literature by examining these associations among a diverse sample of youth. Respondents who participated in only clubs while in school, at the time of the survey, show to have a decrease in criminality and are less likely to report being arrested as an adult, however fewer and fewer clubs are being offered in the school setting. Involvement in clubs is being pushed more in the direction of secondary organizations such as the YMCA or Boys and Girls Clubs (Grossman et al. 2001). Unfortunately while these organizations are great, they are not available for all students; reasons such as there's no nearby location, parents have to transport kids to the location, or parents cannot afford the program fees (2001). My research brings to light the importance and need that schoolbased clubs can have on limiting the criminal activity and arrests of a youth as they enter adulthood.

The idea of educational reform is not a new concept. However, providing more evidence to the importance school institutions play in shaping youth outcomes could help decrease the incarceration rate of the US prison system, in addition to giving more school-aged kids the skills and tools to have more successful and positive lives as they grow into adults. Overall, this research adds to a growing body of literature on the positive impact that school has on the development of youth through the attachments they 
make, as well the involvement opportunities that are provided to them by the school. In an era where school focus has greatly shifted on more time in the classroom and less time on the "extras" it is important to understand what benefit and associations that the "extras" have on students outcomes before it is too late. 


\section{Tables:}

\begin{tabular}{|c|c|c|c|c|}
\hline & Mean/Proportion & S.D. & Min. & Max. \\
\hline Independent Variable (Wave I) & & & & \\
\hline Adolescent Attachment & 3.57 & 0.9 & 0 & 5 \\
\hline \multicolumn{5}{|l|}{ Adolescent Involvement } \\
\hline Sports only Involvement & 0.24 & & 0 & 1 \\
\hline Clubs only Involvement & 0.2 & & 0 & 1 \\
\hline Mixed activities Involvement & 0.35 & & 0 & 1 \\
\hline No Involvement & 0.14 & & 0 & 1 \\
\hline \multicolumn{5}{|l|}{ Dependent Variables (Wave IV) } \\
\hline Arrested as an Adult & 0.3 & & 0 & 1 \\
\hline Criminality as Adult & 0.44 & 1.4 & 0 & 30 \\
\hline \multicolumn{5}{|l|}{ Controls (Wave I) } \\
\hline Male & 0.51 & & 0 & 1 \\
\hline Female & 0.49 & & 0 & 1 \\
\hline White & 0.67 & & 0 & 1 \\
\hline Black & 0.15 & & 0 & 1 \\
\hline Asian & 0.03 & & 0 & 1 \\
\hline Other & 0.07 & & 0 & 1 \\
\hline Native American & 0.04 & & 0 & 1 \\
\hline Hispanic/Latino & 0.11 & & 0 & 1 \\
\hline Age (Wave IV) & 28.9 & 1.8 & 24 & 35 \\
\hline SES (Parents Education) & 1.71 & & 0 & 5 \\
\hline Adolescent Criminality & 3.29 & 4.6 & 0 & 42 \\
\hline
\end{tabular}


Table 2. Odds Ratios and Standard Errors from Logistic Regressions Predicting Ever Arrested in Adulthood $(0=$ no $1=$ yes $)(\mathrm{N}=3,614)$ Models $1-3$

\begin{tabular}{|c|c|c|c|c|c|c|c|c|c|}
\hline \multirow{3}{*}{ Attachment } & \multicolumn{3}{|c|}{ Model 1} & \multicolumn{3}{|c|}{ Model 2} & \multicolumn{3}{|c|}{ Model 3} \\
\hline & $\operatorname{Exp}(B)$ & S.E. & & $\operatorname{Exp}(B)$ & S.E. & & $\operatorname{Exp}(B)$ & S.E. & \\
\hline & 0.78 & 0.05 & $* * *$ & & & & 0.8 & 0.05 & $* * *$ \\
\hline \multicolumn{10}{|l|}{$\begin{array}{l}\text { School involvement } \\
\text { ref=no involvement }\end{array}$} \\
\hline Sports Only Extra. & & & & 1.01 & 0.1 & & 1.1 & 0.12 & \\
\hline Clubs Only Extra. & & & & 0.37 & 0.13 & $* * *$ & 0.42 & 0.14 & $* * *$ \\
\hline Mixed Extra. & & & & 0.58 & 0.1 & $* * *$ & 0.65 & 0.12 & $* * *$ \\
\hline \multicolumn{10}{|l|}{ Female } \\
\hline \multicolumn{10}{|l|}{ Age } \\
\hline \multicolumn{10}{|l|}{ Parents Education } \\
\hline \multicolumn{10}{|l|}{ Black } \\
\hline \multicolumn{10}{|l|}{ Asian } \\
\hline \multicolumn{10}{|l|}{ Native Amer. } \\
\hline \multicolumn{10}{|l|}{ Other } \\
\hline \multicolumn{10}{|l|}{ Hispanic } \\
\hline \multicolumn{10}{|l|}{ Criminality as Youth } \\
\hline \multicolumn{10}{|c|}{$\begin{array}{l}\text { School Attachment x } \\
\text { Gender }\end{array}$} \\
\hline \multicolumn{10}{|c|}{ AttachXFemale } \\
\hline \multicolumn{10}{|c|}{$\begin{array}{l}\text { School Involvement x } \\
\text { Gender } \\
\text { ref=no involvement, } \\
\text { males }\end{array}$} \\
\hline \multicolumn{10}{|l|}{ SportsXFemale } \\
\hline \multicolumn{10}{|l|}{ ClubsXFemale } \\
\hline \multicolumn{10}{|l|}{ MixedXFemale } \\
\hline Constant & $\operatorname{Exp}($ & .92 & & $\operatorname{Exp}($ & 3) $.56^{* * *}$ & & Exp & B) 1.12 & \\
\hline -2 Log Likelihood & 341 & 7.28 & & & 48.23 & & & 8.389 & \\
\hline
\end{tabular}


Table 2 Continued. Odds Ratios and Standard Errors from Logistic Regressions Predicting Ever Arrested in Adulthood $(0=$ no $1=$ yes $)(\mathrm{N}=3,614)$ Models $4-6$

\begin{tabular}{|c|c|c|c|c|c|c|c|c|c|}
\hline \multirow[b]{3}{*}{ Attachment } & \multicolumn{3}{|c|}{ Model 4} & \multicolumn{3}{|c|}{ Model 5} & \multicolumn{3}{|c|}{ Model 6} \\
\hline & $\operatorname{Exp}(B)$ & S.E. & & $\operatorname{Exp}(B)$ & S.E. & & $\operatorname{Exp}(B)$ & S.E. & \\
\hline & 0.78 & 0.05 & $* * *$ & 0.89 & 0.05 & $*$ & 0.87 & 0.07 & $*$ \\
\hline \multicolumn{10}{|l|}{$\begin{array}{l}\text { School involvement } \\
\text { ref=no involvement }\end{array}$} \\
\hline Sports Only Extra. & 0.95 & 0.13 & & 0.92 & 0.13 & & 1.49 & 0.24 & \\
\hline Clubs Only Extra. & 0.54 & 0.15 & $* * *$ & 0.55 & 0.15 & $* * *$ & 0.43 & 0.21 & $* * *$ \\
\hline Mixed Extra. & 0.8 & 0.13 & $* * *$ & 0.75 & 0.13 & $*$ & 0.67 & 0.17 & $* *$ \\
\hline Female & 0.27 & 0.09 & $* * *$ & 0.3 & 0.09 & $* * *$ & 0.16 & 0.41 & $* * *$ \\
\hline Age & 0.99 & 0.03 & & 0.99 & 0.03 & & 0.99 & 0.03 & \\
\hline Parents Education & 0.87 & 0.04 & $* * *$ & 0.86 & 0.04 & $* * *$ & 0.86 & 0.04 & $* * *$ \\
\hline Black & 1.43 & 0.13 & $* *$ & 1.46 & 0.13 & $* *$ & 1.47 & 0.13 & $* *$ \\
\hline Asian & 0.6 & 0.38 & & 0.49 & 0.4 & & 0.49 & 0.4 & \\
\hline Native Amer. & 1.26 & 0.23 & & 1.11 & 0.23 & & 1.09 & 0.24 & \\
\hline Other & 1.35 & 0.19 & & 1.22 & 0.2 & & 1.24 & 0.2 & \\
\hline Hispanic & 0.77 & 0.24 & & 0.643 & 0.26 & & 0.66 & 0.26 & \\
\hline Criminality as Youth & & & & 1.14 & 0.01 & $* * *$ & 1.14 & 0.01 & $* * *$ \\
\hline $\begin{array}{l}\text { School Attachment x } \\
\text { AttachXFemale }\end{array}$ & & & & & & & 1.06 & 0.11 & \\
\hline \multicolumn{10}{|c|}{$\begin{array}{l}\text { School Involvement x Gender } \\
\text { ref=no involvement, males }\end{array}$} \\
\hline SportsXFemale & & & & & & & 0.49 & 0.29 & $* *$ \\
\hline ClubsXFemale & & & & & & & 1.83 & 0.31 & \\
\hline MixedXFemale & & & & & & & 1.35 & 0.27 & \\
\hline Constant & \multicolumn{3}{|c|}{$\operatorname{Exp}(B) 3.11$} & \multicolumn{3}{|c|}{$\operatorname{Exp}(B) 1.03$} & \multicolumn{3}{|c|}{$\operatorname{Exp}(B) 1.21$} \\
\hline -2 Log Likelihood & \multicolumn{3}{|c|}{3129.615} & \multicolumn{3}{|c|}{2965.15} & \multicolumn{3}{|c|}{2956.392} \\
\hline
\end{tabular}


Table 3. OLS Regression Models for Criminality as Adult $(\mathrm{N}=3,614)$ Models $1-3$

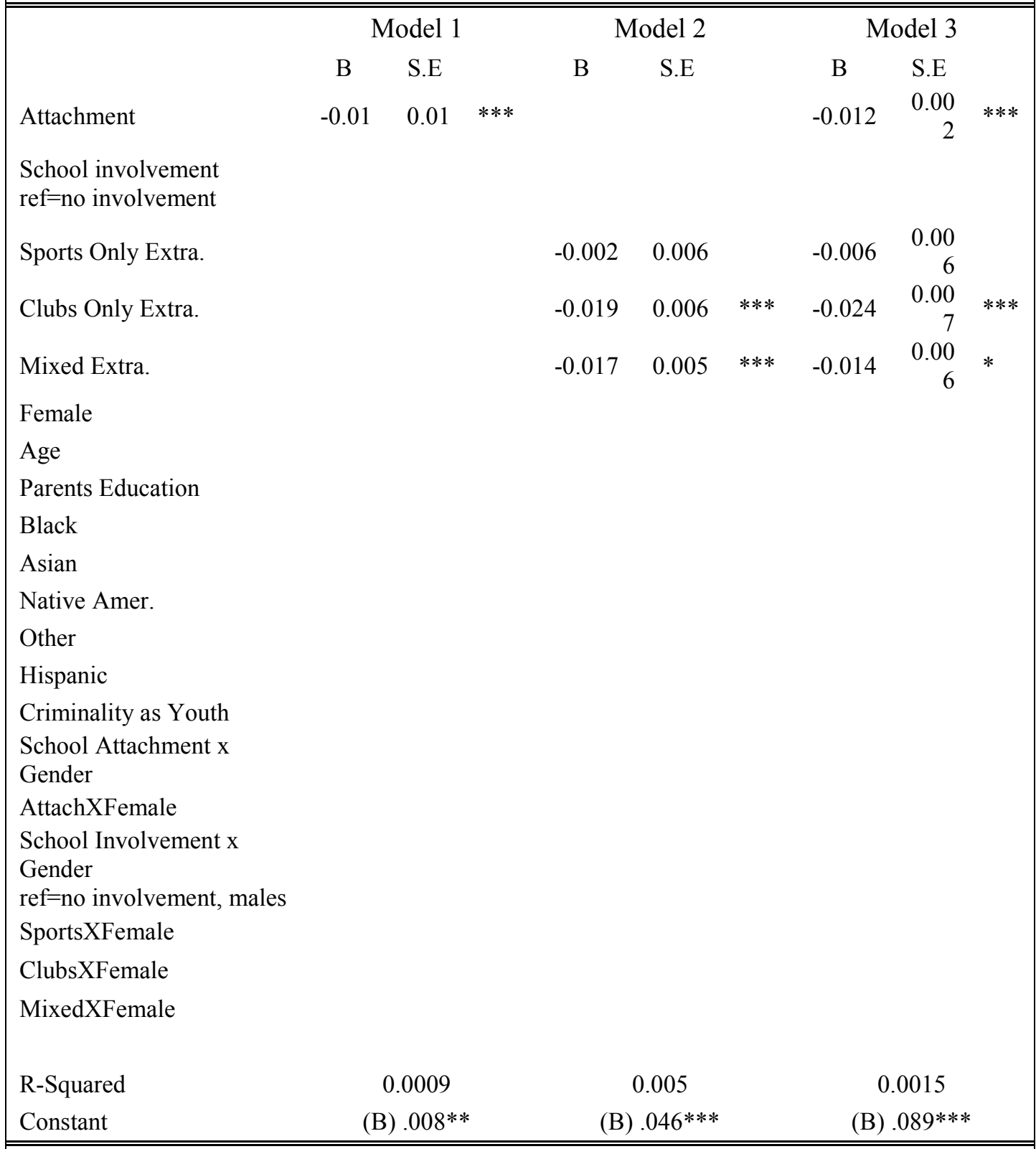

Source: Waves I and IV of the National Longitudinal Survey of Adolescent to Adult Health; Note: $+\mathrm{p}<1 * \mathrm{p}<.05,{ }^{* *} \mathrm{p}<.01, * * * \mathrm{p}<.001$ 
Table 3 Continued. OLS Regression Models for Criminality as Adult $(\mathrm{N}=3,614)$ Models $4-6$

\begin{tabular}{|c|c|c|c|c|c|c|c|c|c|}
\hline & Moc & 14 & & & odel 5 & & & odel 6 & \\
\hline & B & S.E & & B & S.E & & B & S.E & \\
\hline Attachment & -0.012 & 0.002 & $* * *$ & -0.008 & 0.002 & $* * *$ & -0.014 & 0.003 & $* * *$ \\
\hline $\begin{array}{l}\text { School involvement } \\
\text { ref=no involvement }\end{array}$ & & & & & & & & & \\
\hline Sports Only Extra. & -0.013 & 0.006 & $*$ & -0.014 & 0.006 & $*$ & -0.013 & 0.01 & $(+)$ \\
\hline Clubs Only Extra. & -0.018 & 0.007 & $* *$ & -0.016 & 0.007 & $*$ & -0.021 & 0.01 & $*$ \\
\hline Mixed Extra. & -0.013 & 0.006 & $*$ & -0.014 & 0.006 & $*$ & -0.017 & 0.009 & $*$ \\
\hline Female & -0.034 & 0.004 & $* * *$ & -0.028 & 0.004 & $* * *$ & -0.079 & 0.018 & $* * *$ \\
\hline Age & -0.006 & 0.001 & $* * *$ & -0.005 & 0.001 & $* * *$ & -0.005 & 0.001 & $* * *$ \\
\hline Parents Education & -0.001 & 0.002 & & -0.001 & 0.002 & & -0.001 & 0.002 & \\
\hline Black & 0.02 & 0.015 & $* * *$ & -0.019 & 0.006 & & 0.02 & 0.006 & $* * *$ \\
\hline Asian & 0.011 & 0.015 & & 0.008 & 0.015 & & 0.008 & 0.015 & \\
\hline Native Amer. & 0.009 & 0.011 & & 0.006 & 0.011 & & 0.005 & 0.011 & \\
\hline Other & 0.024 & 0.009 & $*$ & 0.021 & 0.009 & $*$ & 0.021 & 0.009 & $*$ \\
\hline Hispanic & -0.024 & 0.011 & $*$ & -0.027 & 0.011 & $*$ & -0.027 & 0.011 & $*$ \\
\hline $\begin{array}{l}\text { Criminality as Youth } \\
\text { School Attachment x } \\
\text { Gender }\end{array}$ & & & & 0.004 & 0 & $* * *$ & 0.004 & 0 & $* * *$ \\
\hline AttachXFemale & & & & & & & -0.013 & 0.005 & $* *$ \\
\hline $\begin{array}{l}\text { School Involvement x } \\
\text { Gender } \\
\text { ref=no involvement, } \\
\text { males }\end{array}$ & & & & & & & & & \\
\hline SportsXFemale & & & & & & & -0.002 & 0.013 & \\
\hline ClubsXFemale & & & & & & & -0.004 & 0.013 & \\
\hline MixedXFemale & & & & & & & -0.006 & 0.012 & \\
\hline R-Squared & 0.0 & & & & .065 & & & .068 & \\
\hline Constant & (B) .2 & $9 * * *$ & & & $236 * * *$ & & & $256 * * *$ & \\
\hline
\end{tabular}




\section{References}

Anderson, Patricia \& Butcher, Kristin. (2006). "Childhood obesity: trends and potential causes." Future Child. Spring 16(1), 19-45.

Agans, Jennifer P., Robey B. Champine, Lisette M. DeSouza, Megan K. Mueller, Sara K. Johnson and Richard M. Lerner. (2014). "Activity Involvement as an Ecological Asset:

Profiles of Participation and Youth Outcomes." Journal of Youth and Adolescence, 43(6), 919-932

Add Health. (2014). "School Questionnaire Wave 1."

http://www.cpc.unc.edu/projects/addhealth/codebooks/wave1

Agnew R., \& Petersen D. (1989). "Leisure and Delinquency." Social Problems, 36, 332350

Akers, R., \& Sellers, C. (2004). "Criminological Theories: Introduction, Evaluation and Application.” Los Angeles: Roxbury Publishing.

American Psychological Association Zero Tolerance Task Force. (2008). "Are zero tolerance policies effective in the schools?" An evidentiary review and recommendations. American Psychologist, 63(9), 852-862.

Arum, R. (2005). Schools and communities: Ecological and institutional dimensions. In Annual Review of Sociology, 26(1), 395-418.

Bachman, Jerald G., Patrick M. O’Malley, John E. Schulenberg, Lloyd D. Johnston, Alison L. Bryant, and Alicia C. Merline. 2002. The Decline of Substance Use in Young Adulthood.

Bassinette, Robert. (2004). "The Relative Impact of Individual and School-Level Factors on Student Attachment to School: An Analysis Using the NELS." University of San Francisco.

Broh, Beckett A. (2002). "'Linking Extracurricular Activity to Academic Achievement: Who Benefits and Why?' Sociology of Education, 75, 69-95

Cahn, S. K. (1993). "From the "Muscle Moll" to the "Butch" Ballplayer: Mannishness, Lesbianism, and Homophobia in U.S. Women's Sport." Feminist Studies, 19, 343-368.

Cauffman, E., \& Steinberg, L. (2000). “(Im)maturity of Judgment in Adolescence: Why Adolescents May be Less Culpable than Adults." Behavioral Sciences \& the Law, 18(6), $741-760$.

Childs, K. K., R. Dembo, S. Belenko, C. J. Sullivan, and J. K. Cochran. (2011). “A Group-Based Approach to Examining the Association among Problem Behaviors in a Sample of Newly Arrested Juvenile Offenders." Youth Violence and Juvenile Justice 9, 313-332. 
Clark, Sheryl. (2012). "Being 'Good at Sport': Talent, Ability and Young Women's Sporting Participation." Sociology, 46(6), 1178-1193

Collishaw, S., Pickles, A., Messer, J., Rutter, M., Shearer, C., \& Maughan, B. (2007). "Resilience to Adult Psychopathology Following Childhood Maltreatment: Evidence from a Community Sample.” Child Abuse \& Neglect, 31, 211-229.

Coker, J., \& Borders, L. (2001). "An analysis of environmental and social factors affecting adolescent problem drinking." Journal of Counseling \& Development, 79, 200208.

Devers, Kara. 2014. "Teacher Child Interaction Training (TCIT) Creates a Positive Classroom Environment: Improving Attachment and Management of Child Behavior Problems." Order No. 3637317 dissertation, James Madison University, Ann Arbor.

Dumais, Susan A. (2008) "Cohort and Gender Differences in Extracurricular Participation: The Relationship Between Activities, Math Achievement, and College Expectations." Sociological Spectrum, 29(1), 72-100.

Eccles, Jacquelynne S., Bonnie L. Barber, Margaret Stone, and James Hunt. (2003). "Extracurricular activities and adolescent development." Journal of Social Issues, 59 (4), $865-89$.

Educational Testing Service (ETS). (1996). "Educational Testing Service Nation's prison population growing, but not educationally."

Eitle, Tamela McNulty. (2005). "Do Gender and Race Matter? Explaining the Relationship Between Sports Participation and Achievement." Sociological Spectrum, 25,177-195.

Gamoran, Adam. (1990). "The Variable Effects of Tracking: Inequality and Productivity in American High Schools." Office of Educational Research and Improvement.

Gilman, R. (2001). "The relationship between life satisfaction, social interest, and frequency of extracurricular activities among adolescent students." Journal of Youth and Adolescence, 30(6), 749-767.

Goldson, Barry, and John Muncie. (2006). "Youth Crime and Justice." London: Sage Publications.

Grossman, Jean, Walker, Karen, \& Raley, Rebecca. (2001). "Challenges and Opportunities in After-School Programs: Lessons for Policymakers and Funders." PPV.

Guest, Andrew M. (2009). "A School-Level Analysis of Adolescent Extracurricular Activity, Delinquency, and Depression: The Importance of Situational Context". Journal of youth and adolescence, 38(1), 51 . 
Hagan, John, Hewitt, John, and Alwin Duane. (1979). "Ceremonial Justice: Crime and Punishment in a Loosely Coupled System.” Social Justice, 58:506-527.

Harris, K. (2007). “Design Features of Add Health.” Carolina Population Center. UNC Chapel Hill.

Hawkins JD, Catalano RF, Miller JY. (1992). "Risk and protective factors for alcohol and other drug problems in adolescence and early adulthood: Implications for substance abuse prevention." Psychological Bulletin, 112:64-105.

Hirschi, T. (1969). "Causes of Delinquency.” Berkeley, CA: University of California Press.

Hirschfield, P. J., and Gasper, J. (2011). "The relationship between school engagement and delinquency in late childhood and early adolescence." Journal of Youth and Adolescence, 40(1), 3-22.

Hoffmann, John P., Lance D. Erickson and Karen R. Spence. (2013). "Modeling the Association between academic achievement and Delinquency: An Application of Interactional Theory." Criminology 51(3):629-660.

Kaufman J and Gabler J. (2004). "Cultural Capital and the Extracurricular Activities of Girls and Boys in the College Attainment Process." Poetics, 32(2), 145-68.

Kort-Butler, L. A., \& Hagewen, K. J. (2011). "School-based extracurricular activity involvement and adolescent self-esteem: A growth-curve analysis." Journal of Youth and Adolescence, 40, 568-581.

Landers, Daniel. (1978). "Socialization via Interscholastic Athletics: Its Effects on Delinquency and Educational Attainment". Sociology of education, 51(4), 299.

Lilly, Robert J., Cullen, Francis T., \& Ball, Richard A. (2011). “Criminological Theory: Context and Consequences." SAGE Publications 5th Edition.

Lleras, Christy. (2008). "Do skills and behaviors in high school matter? The contribution of noncognitive factors in explaining differences in educational attainment and earnings." Social Science Research, 37 (3): 888-902.

Loukas, A., Roalson, L. A., \& Hererra, D. E. (2010). "School connectedness buffers the effects of negative family relations and poor effortful control on early adolescent conduct problems." Journal of Research on Adolescence, 20, 13-22.

Maddox, S., \& Prinz, R. (2003). "School bonding in children and adolescents:

Conceptualization, assessment, and associated variables." Clinical Child and Family

Psychology Review, 6(1), 31-49. 
Mahoney, J. L., Harris, A. L., \& Eccles, J. S. (2006). “Organized activity participation, positive youth development, and the overscheduling hypothesis." Society for Research in Child Development: Social Policy Report, 20, 1-30.

Marsh, H., \& Kleitman, S. (2002). Extracurricular school activities: The good, the bad, and the nonlinear.

Martin, M. (1998). "The use of alcohol among NCAA Division I female college basketball, softball, and volleyball athletes." Journal of Athletic Training, 33(2), 163167.

Mendel, Richard. (2001). "Less Cost, More Safety: Guiding Lights for Reform in Juvenile Justice." Youth Policy Forum, 11-13.

Metsapelto, Riitta-Leena and Lea Pulkkinen. (2012). "Socioemotional Behavior and School Achievement in Relation to Extracurricular Activity Participation in Middle Childhood." Scandinavian Journal of Educational Research, 56(2),167-182.

Moore, Kristin \& Halle, Tamara G. (2001). "Preventing Problems vs. Promoting the Positive: What Do We Want for Our Children." Advances in Life Course Research. 6:141-170.

Noam, G.G. \& Fiore, N. (2004). "Relationships across multiple settings: An overview. New Directions for Youth Development" 103, 9-16.

Northeastern University. (2008). Can Involvement In Extra-curricular Activities Help Prevent Juvenile Delinquency? ScienceDaily.

Pager, Devah. (2007). Marked: "Race, Crime, and Finding Work in an Era of Mass Incarceration." University of Chicago Press.

Price, Heather. (2010). "Does No Child Left Behind Really Capture School Quality? Evidence on Urban School District." Educational Policy, 24(5), 778-814.

Resnick MD, Bearman PS, Blum RW, Bauman KE, Harris KM, Jones J, Tabor J, Beuhring T, Sieving RE, Shew M, Ireland M, Bearinger LH, Udry JR. (1998). "Protecting adolescents from harm: findings from the National Longitudinal Study on Adolescent." McGraw-Hill College, 376-95.

Roth, J., Brooks-Gunn, J., \& Galen, B, (1997). "Promoting healthy adolescence: Youth development frameworks and programs." Center for Children and Families, Teachers College, Columbia University, New York.

Sampson, Robert \& Laub, J. (1990). "Crime and deviance over the life course: The salience of adult social bonds." American sociological review, pp. 609-627. 
Slavkin, M. (2001). "How can awareness of gender identity improve the performance of students?" Journal of College Reading and Learning, 32, 32-40.

Snellman, Kaisa, Jennifer M. Silva, Carl B. Frederick and Robert D. Putnam. 2015. "The Engagement Gap: Social Mobility and Extracurricular Participation among American Youth." The Annals of the American Academy of Political and Social Science, 657(1), 194-207.

Snyder, H.N. (2004). "An empirical portrait of the youth reentry population" Youth Violence and Juvenile Justice, 2 (1), 39-55.

Strolin-Goltzman, J., Sisselman, A., Melekis, K., and Auerbach, C. (2014).

"Understanding the relationship between school-based health center use, school connection, and academic performance." Health \& Social Work, 39(2), 83-91.

Stuart, M. (2011). "The impact of engagement with extracurricular activities on the student experience and graduate outcomes for widening participation populations". Active learning in higher education, 12(3), 203.

Travis, Jeremy. (2002). “Invisible Punishment: An Instrument

of Social Exclusion.” The Collateral Consequences of Mass Imprisonment. Pp. 15-36

Thornberry, T., Lizotte, A., Krohn, M., Farnworth, M., \& Jang, S. (1991). "Testing interactional theory: An examination of reciprocal causal relationships among family, school, and delinquency." The Journal of Criminal Law and Criminology, 82, 3-35.

Unnever \& Gabbidon. (2011). "A theory of African American offending: Race, racism, and crime." New York, NY: Routledge.

Wankel, L., \& Berger, B. (1990). "The psychological and social benefits of sport and physical activity.” Journal of Leisure Research, 22, 167-182.

Wyrwich, Tom. (2009). "The cost of playing high-school sports is on the rise." The Seattle Times. 